\title{
OBAMA: um Repositório de Objetos de Aprendizagem para Matemática
}

\author{
Samuel Dantas Batista ${ }^{1}$, Rodolfo Araújo de Carvalho ${ }^{1}$, Amanda Maria Domingos \\ de Oliveira ${ }^{1}$, Ana Cláudia Nunes Silva ${ }^{2}$, Nelson Ion de Oliveira ${ }^{1}$, Dennys Leite \\ Maia $^{1}$
}

${ }^{1}$ Instituto Metrópole Digital - Universidade Federal do Rio Grande do Norte Av. Sen. Salgado Filho, 3000 - Lagoa Nova, CEP: 59.078-970 - Natal - RN - Brasil

${ }^{2}$ Centro de Educação - Universidade Federal do Rio Grande do Norte

\{samueldantas 7, amanda.marry\} @hotmail.com, \{rodolfooac, anna.claudia.nunes\}@gmail, \{nelson, dennys\}@imd.ufrn.br

Resumo. Este artigo apresenta o protótipo da segunda versão do repositório Objetos de Aprendizagem para Matemática (OBAMA), desenvolvido com o propósito de ser uma plataforma que ofereça ao professor da Educação Básica acesso, em único endereço web, ao maior número de objetos de aprendizagem (OA) e espaço para produção e compartilhamento de planos de aula com os recursos. O OBAMA 2.0 disponibiliza 498 OA, classificados por critérios pedagógicos e técnicos, que contemplam dispositivos desktop e mobile. A plataforma possui sistema de busca por OA por título, níveis de ensino da Educação Básica, temas curriculares da Matemática e descritores, além de uma função para a produção e compartilhamento de planos de aula.

\section{Cenário de uso}

As Tecnologias Digitais de Informação e Comunicação (TDIC) transformaram a forma como nos comunicamos e construímos conhecimento. Novas ferramentas e interfaces facilitam a interação e a discussão, além de criarem possibilidades de trabalho colaborativo, trazendo aos usuários a possibilidade de passar de consumidores passivos a criadores e coautores de conteúdos e serviços [Santana, Campos-Pinto e Costa 2015].

Dentro desse contexto é importante que o currículo escolar e o planejamento docente contemplem o uso dessas ferramentas, uma vez em que estão cada vez mais presentes no cotidiano de alunos e professores. Recursos educativos digitais podem contribuir para o ensino e a aprendizagem da Matemática em diferentes dimensões. Alguns objetos de aprendizagem (OA) podem animar e simular situações do cotidiano que envolvem conceitos matemáticos, facilitando sua percepção e apreensão [CastroFilho et al 2016].

Muitos professores, entretanto, ainda sequer conhecem a existência de OA, muito menos as possibilidades que podem se servir deles. Nesse sentido, a criação de repositórios, alinhada a uma formação continuada docente, como a pretendida no projeto a qual este trabalho está inserido, pode contribuir para mudança dessa realidade. Ao disporem de novos recursos didáticos, os professores podem incluí-los e passar a integrá-los em suas aulas.

A partir dessa problemática é que foi concebido o repositório Objetos de Aprendizagem para Matemática (OBAMA), com a proposta oferecer aos professores de 
Matemática da Educação Básica um ambiente que ofereça acesso, em único endereço web, ao maior número de OA para as suas aulas, com a indicação da etapa de ensino, tema curricular e a confiabilidade das características pedagógicas do recurso, além de espaço para produção e compartilhamento de planos de aula com os OA.

A primeira versão do referido repositório partiu de uma iniciativa do Grupo de Pesquisa Matemática e Ensino (MAES) da Universidade Estadual do Ceará (UECE), também desenvolvida pelo atual coordenador do projeto em 2013 [Maia et al 2017]. O repositório dispunha de 261 OA organizados por nome, nível de ensino e blocos de conteúdo e disponibilizados em outros repositórios de objetos de aprendizagem (ROA), como a Fábrica Virtual da Rede Interativa Virtual de Informação (Rived), Grupo de Pesquisa e Produção de Ambientes Interativos e Objetos de Aprendizagem (PROATIVA), Mídias Digitais para Matemática da Universidade Federal do Rio Grande do Sul (MDMat/UFRGS), Matemática Multimídia da Universidade Estadual de Campinas ( $\mathrm{M}^{3} / \mathrm{UNICAMP}$ ) e Núcleo de Desenvolvimento de Objetos de Aprendizagem Significativa (NOAS), com OA sob licença Creative Commons ${ }^{1}$ (CC).

A partir do trabalho realizado anteriormente pelo MAES, procedeu-se a uma atualização do repositório o qual denominou-se como OBAMA 2.0. Esta iniciativa faz parte das ações do Grupo Interdisciplinar de Estudos e Pesquisas em Informática na Educação (GIIfE) que, por meio de um trabalho interdisciplinar, procura combinar a visão de profissionais da Educação com a de profissionais da área de Tecnologia da Informação (TI) para o desenvolvimento de tecnologias educacionais. Assim, o OBAMA contou com elementos de design e interação aliados a finalidade pedagógica para a reconstrução do repositório OBAMA.

\section{Desenvolvimento}

O desenvolvimento do OBAMA 2.0 foi realizado em três etapas: (i) pesquisa de OA disponíveis em outros ROA, como também OA encontrados diretamente em sites de busca (Google, Yahoo e Bing); (ii) planejamento do software por meio de diagramas do modelo Unified Modeling Language (UML) e prototipagem de telas; e (iii) fase de implementação, em que foi utilizado o padrão de arquitetura de software Model-ViewController (MVC) e o framework, para desenvolvimento de aplicações web com a linguagem Java, JavaServer Faces (JSF). Na etapa de pesquisa e classificação dos OA, além da catalogação de novos recursos foram discutidos os atributos que seriam importantes para a inclusão nos metadados dos OA.

Pensando na dificuldade e nas necessidades que um profissional da educação tem ao procurar recursos digitais de animação e simulação, que possam ser utilizados em sala de aula para auxiliar o estudante na compreensão dos conteúdos, definiu-se como os atributos de busca: o título do OA, nível de ensino, o tema curricular e descritores da Prova Brasil. A finalidade desses parâmetros é oferecer uma variedade de opções para os professores buscarem recursos para uma temática específica.

Para o OBAMA 2.0 foram catalogados OA para dispositivos desktop e mobile, dando preferência aos $\mathrm{OA}$ de licenças livres e criativas, visando garantir a disponibilidade desses recursos de forma gratuita e permanente. No caso dos aplicativos

1Licença que permite a qualquer interessado fazer uso, compartilhamento e alterações (ou não) em determinado recurso, desde que sejam mantidas as referências a autores e colaboradores anteriores. 
para dispositivos móveis, foi dada preferência aos que funcionam em sistema operacional Android, por ser um sistema presente na maioria dos tablets e smartphones e funcionar em dispositivos de baixo custo, possibilitando o acesso de um maior número de pessoas. Foram catalogados 184 aplicativos para dispositivos móveis de sete repositórios, sendo o Google Play a principal fonte de OA. Dos OA para dispositivos desktop, foram catalogados 133 OA de dezoito repositórios. Após análise dos recursos catalogados, contando com os 261 OA que já estavam disponíveis na primeira versão do OBAMA, foram retirados os OA repetidos ou com problema de funcionamento e atualmente o OBAMA 2.0 disponibiliza 498 OA para dispositivos móveis e desktop.

A etapa de planejamento e organização do sistema, foi realizada levando em consideração a finalidade pedagógica do projeto e as dificuldades encontradas ao realizar busca de OA em outros repositórios. A falta de organização por metadados, os links quebrados, o difícil acesso as páginas de OA e os resultados incoerentes, foram alguns dos problemas encontrados. Sendo assim, o OBAMA 2.0 foi planejado com o intuito de suprir essas limitações, que podem ser um fator desencorajador ao professor que busca um OA que o auxilie e que de fato proporcione maior compreensão do conteúdo por parte dos estudantes. Assim, por meio de diagramas de classes e de casos de uso, as funcionalidades e características a serem implementadas no repositório foram definidas e documentadas.

A proposta da plataforma do OBAMA 2.0 apresenta espaço para produção, avaliação e compartilhamento de planos de aula, que façam uso dos OA encontrados no repositório. O usuário cadastrado também poderá indicar a inclusão de novos OA a serem adicionados no repositório, assim como os planos de aula, esses OA serão avaliados antes de serem adicionados. Tanto para os planos de aula quanto para os OA, as buscas poderão ser filtradas pelos metadados: nome, tema curricular, níveis de ensino, descritores, este definido de acordo com os Parâmetros Nacionais Curriculares (PCN). Esta funcionalidade dá ao professor recursos para especificar sua busca de acordo com a habilidade que pretende desenvolver com os seus estudantes. Além disso a projeto prevê implementar a funções de: recomendação de OA por meio de ranking com os mais utilizados e com os de maior nota de avaliação; um sistema de verificação de links de OA, para garantir o mínimo possível de OA indisponíveis por links quebrados; e possibilidade de compartilhar esses recursos por meio das redes sociais.

Como se trata de um protótipo, o OBAMA está em fase de desenvolvimento e algumas das funcionalidades citadas acima já foram implementadas e serão apresentadas na seção de apresentação do software.

\section{Apresentação do Software}

O repositório OBAMA é uma plataforma web que não necessita de cadastro para a busca de OA. Porém, seu cadastro é necessário para dar acesso às funcionalidades de plano de aula. A figura 1 apresenta a interface inicial que conta com o menu principal, composto por cinco opções: (i) Projeto, em que é descrito o seu objetivo; (ii) Equipe, onde são apresentados os membros do projeto; (iii) Objetos de Aprendizagem, em que o usuário tem acesso ao formulário de busca de OA; (iv) Planos de aula, para a consulta de planos elaborados por usuários do OBAMA e (v) Entrar, para que o usuário possa se cadastrar e acessar os demais recursos do sistema, como submeter planos de aulas e avaliar OA. 
VI Congresso Brasileiro de Informática na Educação (CBIE 2017)

Anais dos Workshops do VI Congresso Brasileiro de Informática na Educação (WCBIE 2017)

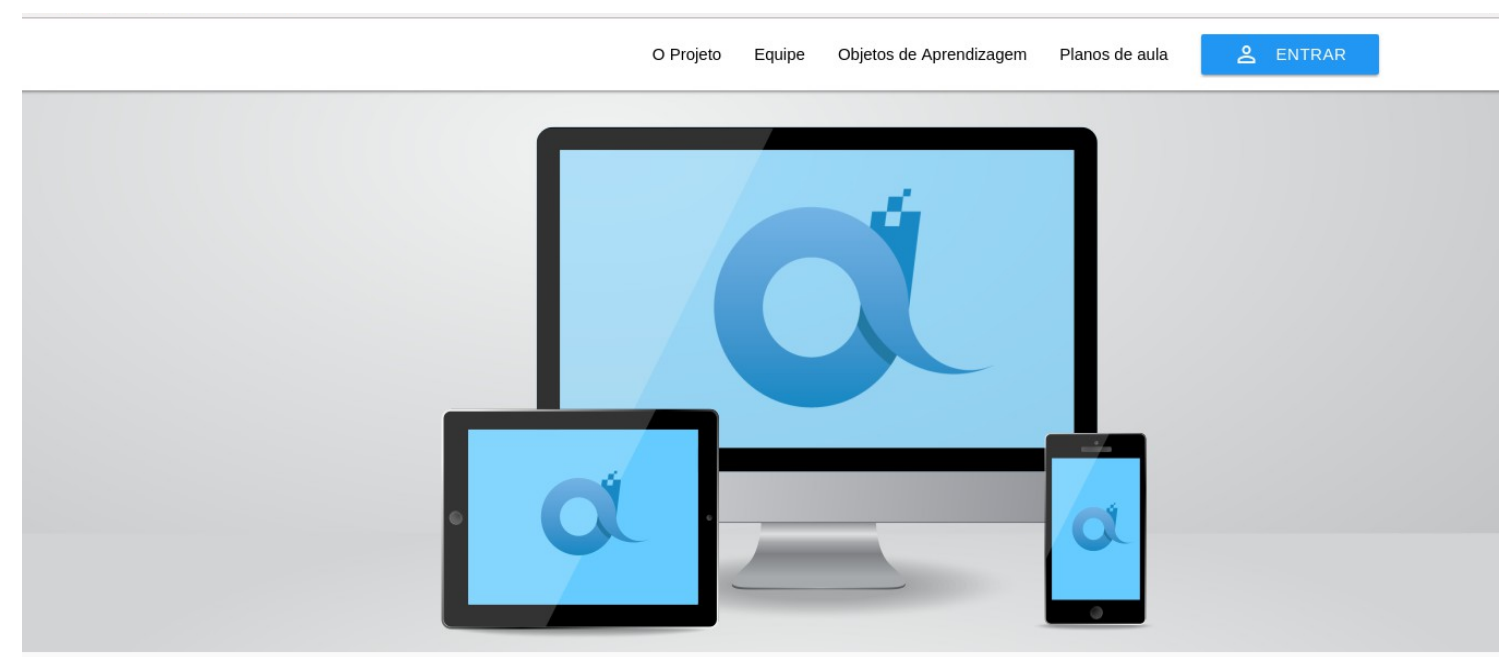

Figura 1. Página Inicial do OBAMA.

\subsection{Busca e acesso a OA}

Para buscar dentro do repositório, o usuário tem os filtros de Nível de Ensino, Tema Curricular e Descritores, como mostra a figura 2. Visto que os OA do OBAMA foram classificados de acordo com os PCN, que norteiam a Prova Brasil. Esses campos facilitam o processo de busca, garantindo uma confiabilidade ao recurso e o relacionando com o tema de interesse.

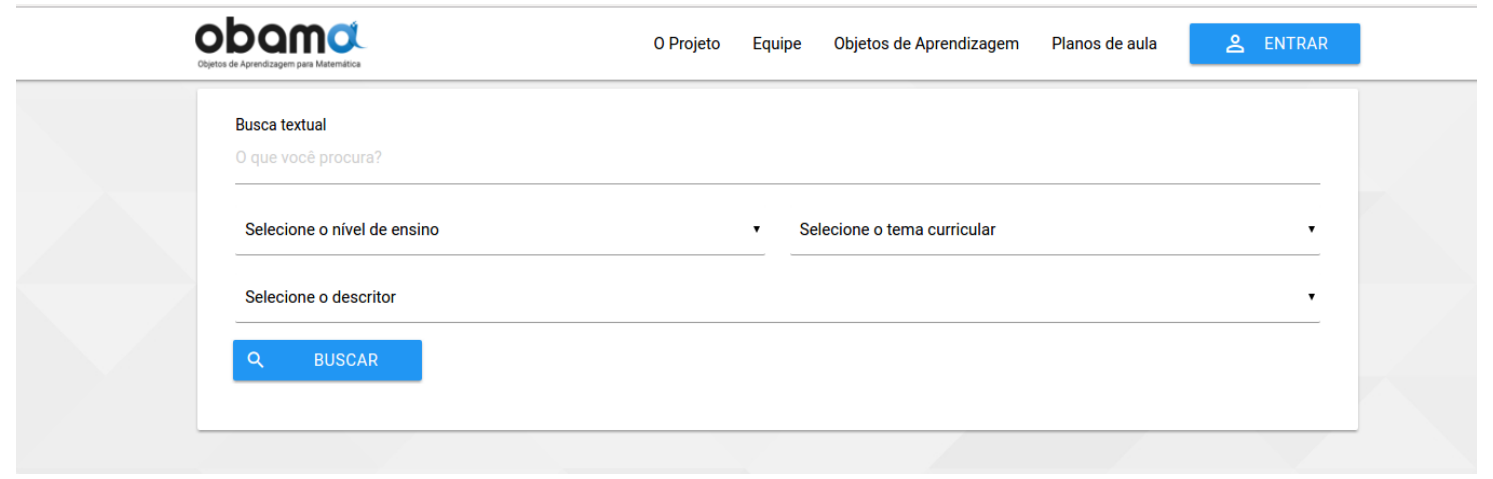

Figura 2. Página de busea do DBAMA.

Ao realizar uma busca, caso sejam encontrados resultados, os OA são apresentados como mostra a figura 3. Essa visualização apresenta, para cada OA, uma imagem relacionada ao OA, seu título, nível de ensino, blocos de conteúdo e um botão de acesso direto ao OA, denominado Visualizar, uma vez que a maior parte dos recursos não demandam instalação para uso. Essas informações servem de referência para o professor pré-avaliar o recurso e sua pertinência para a aula que deseja planejar. 
VI Congresso Brasileiro de Informática na Educação (CBIE 2017)

Anais dos Workshops do VI Congresso Brasileiro de Informática na Educação (WCBIE 2017)

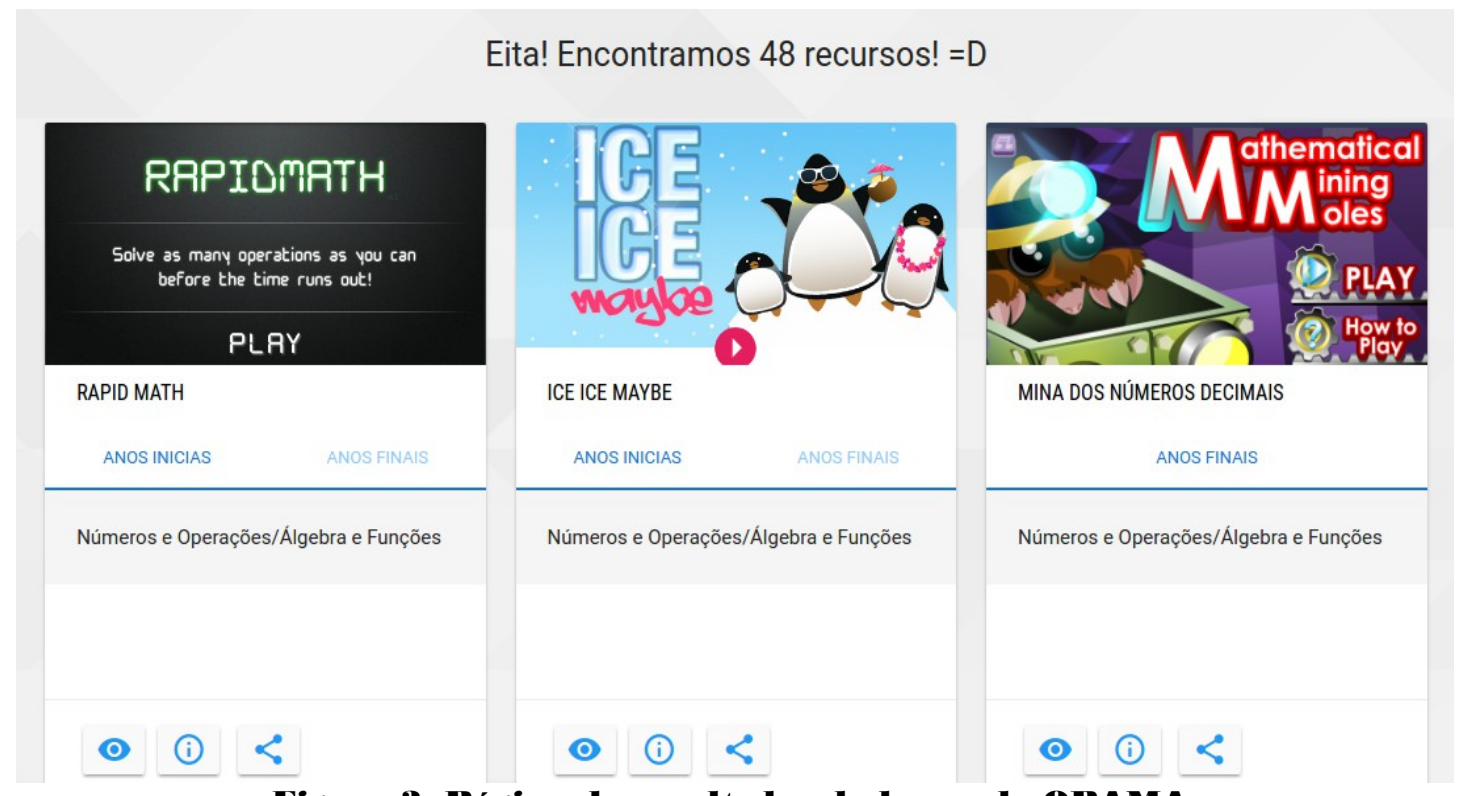

Figura 3. Página de resultados da busca do DBAMA.

Abaixo do botão Visualizar, está o link de Mais Informações (figura 4) que apresenta detalhes relacionados aos descritores. Destaca-se a informação dos descritores, apresentando o nível de ensino a qual eles estão relacionados e a descrição completa, oportunizando ao professor identificar as habilidades que podem ser exploradas com o OA.

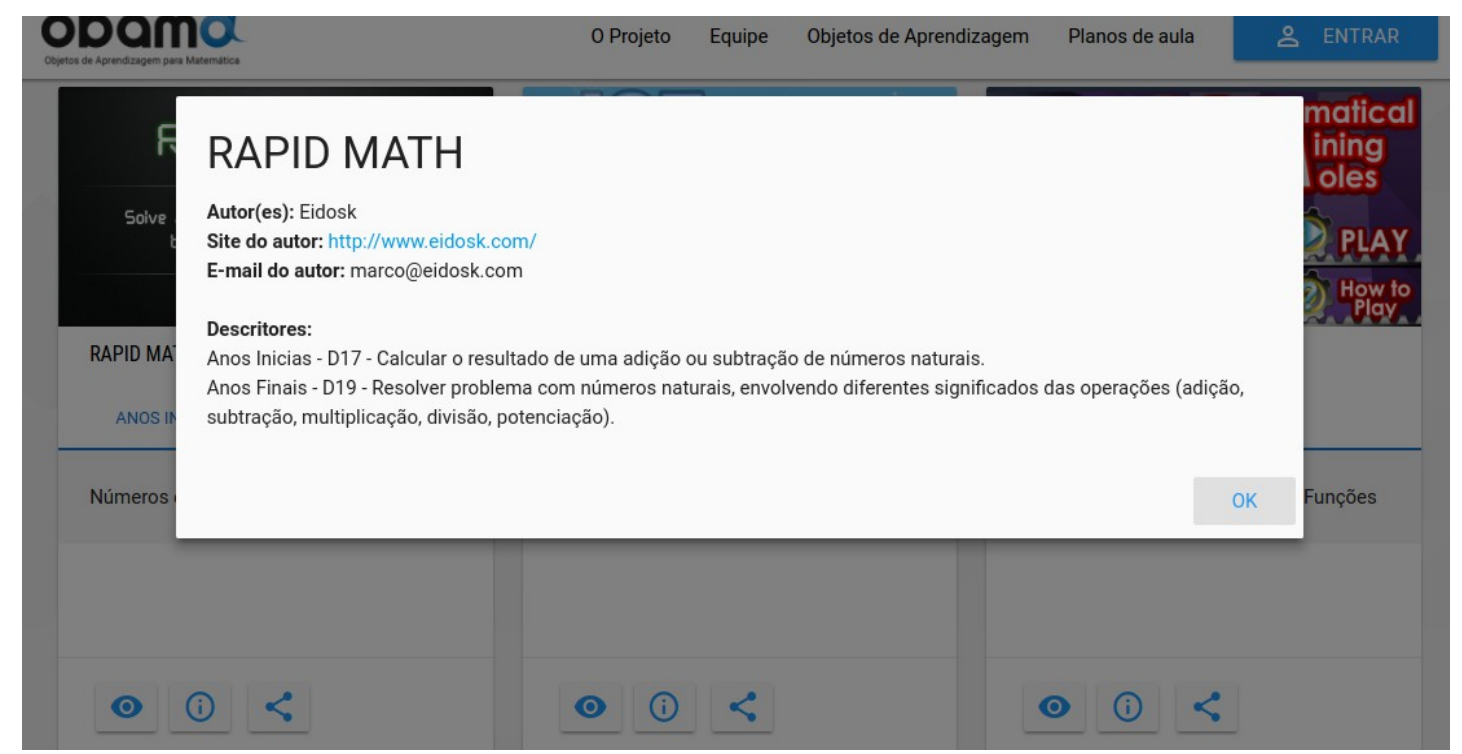

Figurara 4. Mais informações do DA.

Cumpre esclarecer que alguns OA referenciados no OBAMA são acessíveis a partir do site de seus produtores e de outros ROA. Por esta razão, ainda que licenciados sob $C C$, é requerido ao usuário uma autenticação para acesso ao OA. Para evitar que isso se torne um elemento inibidor da adoção do OA pelo professor, o projeto prevê o armazenamento de cada recurso listado no OBAMA em servidor próprio.

\subsection{Cadastro no sistema para submissão de plano de aula}


VI Congresso Brasileiro de Informática na Educação (CBIE 2017)

Anais dos Workshops do VI Congresso Brasileiro de Informática na Educação (WCBIE 2017)

Para acessar as outras funcionalidades do OBAMA, além da busca e acesso a OA, torna-se necessário que o usuário realize seu cadastro no sistema. A partir do botão Entrar, do menu principal, o usuário tem acesso aos formulários de login e cadastro (figura 5). Vale destacar que o usuário pode utilizar sua conta do Google ou Facebook, ambientes bastante populares nos quais muitas pessoas já possuem cadastro, para fazer login no sistema.

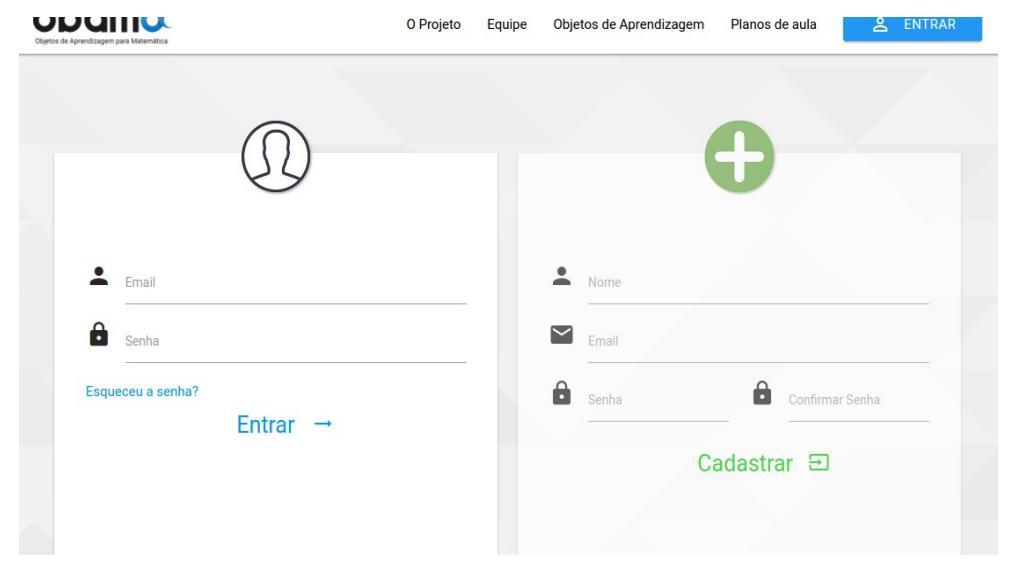

Figura 5. Formulários de login e cadastro.

Com seu cadastro efetivado e realizado o login no sistema, o usuário terá acesso, também, às opções relacionadas ao plano de aula: Novo e Meus Planos de Aula. Ao clicar na opção Novo na seção Plano de aula, o sistema apresentará o formulário de submissão de plano de aula, como mostra a figura 6. Neste formulário, o usuário deve informar os seguintes dados da sua proposta de aula: Título da Aula, Instituição de Ensino, Nível de Ensino, Ano de Ensino (série) e Duração da Aula. Em seguida, o usuário poderá preencher os campos de texto (e que permitem formação) para a descrição detalhada de sua aula. Os campos são: Resumo da Proposta de Aula, Objetivo Geral, Objetivos Específicos, Metodologia/Descrição da Proposta de Aula, Recursos Avaliativos e Referências.

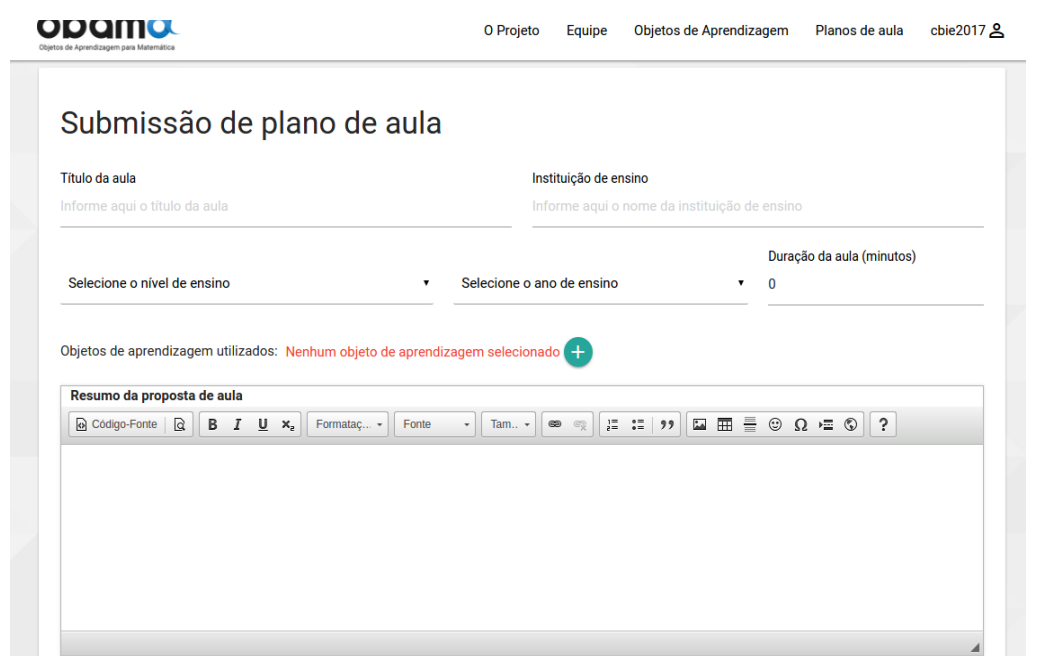

Figura 6: Tela de submissão de plano de aula.

Ao final do preenchimento do formulário, o usuário pode enviar o plano de aula para avaliação ou salvar o rascunho para edições futuras. Essa última função está em fase de implementação. Para acessar os planos de aula já submetidos ou ainda em 
VI Congresso Brasileiro de Informática na Educação (CBIE 2017)

Anais dos Workshops do VI Congresso Brasileiro de Informática na Educação (WCBIE 2017)

rascunho, o usuário deve acessar a opção Meus Planos, no menu Plano de Aula. Com isso, serão listados os seus planos de aula (figura 7).

Meus planos de aula

\begin{tabular}{|c|c|c|c|c|}
\hline \multirow[b]{2}{*}{ Título da aula } & \multirow[b]{2}{*}{ Data de submissāo } & \multicolumn{3}{|c|}{0 que vocé procura? } \\
\hline & & Status & & \\
\hline TESTE & 06/07/2017 & (1) & 0 & $\bar{x}$ \\
\hline asdasdasdas & $25 / 08 / 2017$ & (1) & 0 & $\bar{x}$ \\
\hline
\end{tabular}

Figura 7: Tela de listagem de plano de aula.

Na tela de listagem de Meus planos de aula, é possível, também, Visualizar e Remover um plano de aula. Com essa função, o professor, além de escolher um OA para incrementar suas aulas, ele disporá de um ambiente para facilitar a elaboração e arquivamento de seus planos de aula. Além disso, como esses planos ficarão disponíveis e indexados aos OA, eles poderão estimular outros docentes a explorar e integrar os recursos em suas aulas, ampliando a possibilidade de inovar o ensino de Matemática. As opções de fazer Download do arquivo do plano de aula em formato PDF e Editar, bem como produzir de forma colaborativa estão previstas para serem implementadas em breve.

\section{Considerações Finais}


Por oferecer uma grande quantidade de recursos educativos digitais os ROA podem contribuir para a integração das TDIC nas salas de aula. Entretanto, para que, essa integração realmente ocorra, é necessário que os repositórios sejam desenvolvidos sob o olhar do profissional da Educação e que tenha potencial de alcance a todas as classes sociais. Sob esta perspectiva, os meios de busca, os OA de licenças livres e criativas, e o funcionamento de $\mathrm{OA}$ em diversos tipos de sistemas operacionais (principalmente nos de código-fonte aberto), são características fundamentais para que sejam atendidas as necessidades dos professores e para que os OA tenham alcance ao público de baixa renda.

Todas essas características são apresentadas no OBAMA 2.0. Vale destacar a classificação de objetos de aprendizagem pelos descritores da prova Brasil e o espaço para envio e consulta de planos de aula. A busca de OA pelos descritores da prova Brasil proporcionam agilidade na busca de um OA que trabalhe a habilidade desejada pelo professor, essa é uma funcionalidade muito importante, se se levar em consideração a alta carga de trabalho dos professores de escola pública e que a dificuldade para encontrar um recurso que o auxilie pode ser um fator desmotivador aos professores. A consulta e o envio dos planos de aula relacionados aos OA presentes no OBAMA 2.0 é outra característica importante, por proporcionar um ambiente de troca de informações, ideias e experiência entre os professores.

Ressalta-se, que o repositório OBAMA 2.0 está em fase de desenvolvimento, e ainda não possui todas as funcionalidades propostas no planejamento do software. Ainda falta ser implementadas as funcionalidades de interação e compartilhamento de conteúdo nas redes sociais, os rankings de OA, o espaço para comentários nas páginas dos OA, a busca de planos de aula, o sistema de verificação de links e o espaço para submissão de novos OA. O projeto também deve passar por alterações técnicas e mudanças relativas à interação humano-computador (IHC). Apesar de ainda ter muitas funcionalidades a serem implementadas, o OBAMA 2.0 está disponível e teve o seu primeiro teste em minicurso ofertado em congresso realizado em maio de 2017, em que os participantes utilizaram o repositório para buscar OA e a partir dele propuseram os primeiros planos de aula submetidos no OBAMA 2.0.

\section{Referências}

Castro-Filho, J. A. de; Maia, D. L.; Castro, J. B. de; Barreto, A. L. de O.; Freire, R. S. Das tabuletas aos tablets: tecnologias e aprendizagem da Matemática. In: CastroFilho, J. A. de; Barreto, M. C.; Barguil, P. M.; Maia, D. L.; Pinheiro, J. L. (Orgs.). Matemática, cultura e tecnologia: perspectivas internacionais. Curitiba: CRV, p.1334.

Maia, D. L.; Oliveira, A. M. D. de; Silva, A. C. N.; Costa, C. J. N. da; Brito, D. T. de S.; Melo, E. M. de; Oliveira, N. I. de; Batista, S. D. (2017). Objetos de aprendizagem para Matemática: yes we can!. In: Congresso sobre Tecnologias na Educação (Ctrl+E 2017), Anais... Mamanguape: CEUR-WS, p.744-750.

Santana, C. M. H.; Campos-Pinto, A. de; Costa, C. J. D. S. A. (2015). A ubiquidade das TDIC no cenário contemporâneo e as demandas de novos letramentos e competências na EAD. In: EaD EmRede-Revista de Educação a Distância, v.2., n.1, p.100-115. 